\title{
AVALIAÇÃO DE VARIÁVEIS RESTRITIVAS À QUALIDADE NA EXECUÇÃO DO PROGRAMA NACIONAL DE ALIMENTAÇÃO ESCOLAR COM INSERÇÃO À GESTÃO ESTRATÉGICA DE RECURSOS PÚBLICOS
}

\section{1- José Moreira da Silva Neto*}

Doutor em Engenharia de Produção pela Universidade Federal de Santa Catarina - UFSC, Florianópolis/SC, Brasil. Professor do Programa de Mestrado em Administração da Fundação Universidade Federal de Rondônia - UNIR, Porto Velho/RO, Brasil.

silvanetojm@uol.com.br

http://lattes.cnpq.br/1668946474207000

\section{2- Ricardo Plácido Ribeiro}

Mestre em Administração pela Fundação Universidade Federal de Rondônia - UNIR, Porto Velho/RO, Brasil. ricardo.p.ribeiro@cgu.gov.br

http://lattes.cnpq.br/5878071275283816

\section{3- Haroldo Cristovam Teixeira Leite}

Doutor em Engenharia de Produção pela Universidade Federal de Santa Catarina - UFSC, Florianópolis/SC, Brasil. Professor do Programa de Mestrado em Administração da Fundação Universidade Federal de Rondônia - UNIR, Porto Velho/RO, Brasil.

haroldo@unir.br

http://lattes.cnpq.br/1687874041718039 


\title{
AVALIAÇÃO DE VARIÁVEIS RESTRITIVAS À QUALIDADE NA EXECUÇÃO DO PROGRAMA NACIONAL DE ALIMENTAÇÃO ESCOLAR COM INSERÇÃO À GESTÃO ESTRATÉGICA DE RECURSOS PÚBLICOS
}

\section{RESUMO}

Buscou-se neste artigo associar a arquitetura teórica da gestão estratégica de recursos (ou de desempenho) do Programa Nacional de Alimentação Escolar (PNAE) com os vetores de eliminação da ocorrência de variáveis restritivas ao sucesso do programa. Para avaliação das variáveis utilizou-se o método de análise de conteúdo, aplicada em 197 relatórios da Controladoria Geral da União (CGU), período 2005-2007, confrontados com os princípios de controle do United States Government Accountability Office (GAO) e da Nova Administração Pública (NAP). Sendo que, para a análise da perspectiva de melhoria contínua com propósito de erradicação da ocorrência de tais tipos de variáveis, a metodologia adotada foi da Activity Based in Cost (ABC). A hipótese vislumbrada com esta metodologia consiste em: no orçamento se admite a meta máxima de efetividade, a partir da demanda dos serviços/produtos do PNAE, enquanto que na mensuração do desempenho a meta é a melhoria contínua deste programa, a partir da demanda de recursos. A pesquisa evidenciou a existência de variáveis restritivas à qualidade da gestão do PNAE em $89 \%$ (oitenta e nove por cento) dos municípios auditados pela CGU, sendo que, dos tipos de falhas mais freqüentes, accountability de conformidade correspondeu a patamares próximos a $36 \%$ das falhas evidenciadas no período analisado, seguido da restrição à eficiência do PNAE cujo índice foi de 33\% e das restrições ao controle democrático que corresponderam a aproximadamente $19 \%$ das fragilidades evidenciadas. As falhas restantes referiram-se às restrições aos controles internos e aos resultados.

\author{
Palavras-Chave \\ Gestão Estratégica; Programas e Recursos Públicos.
}

\section{EVALUATION OF RESTRICTIVE VARIABLES TO THE QUALITY IN THE EXECUTION OF A NATIONAL PROGRAM OF SCHOOL FEEDING WITH INSERTION TO STRATEGICAL MANAGEMENT OF PUBLIC RESOURCES}

\begin{abstract}
Search in this article, to associate the theoretical architecture of the strategic management of resources (or performance) of a National Program of School Feed (PNAE) with the vectors of elimination of the occurrence of restrictive variables to the success of the program. For evaluation of the variable the method Content Analysis was used, applied in 197 reports of the General Controllership of the Republic of Brazil (CGU), period 2005-2007, confronted with the principles of control of United States Government Accountability Office (GAO) and of New Public Administration (NAP). Being that, for the analysis of the perspective of continuous improvement with intention of eradication of the occurrence of such types of variable, the adopted methodology was of the Activity Based in Cost (ABC). The hypothesis glimpsed with this methodology consists of: in budget if admits the maximum goal of effectiveness, from the demand of services/products of the PNAE, whereas in the mensuration of the performance the goal is continuous improvement of this program, from the demand of resources. The research evidenced the existence of restrictive variable to the quality of the management of the PNAE in $89 \%$ (eighty and nine percent) of the cities audited for the CGU, being that, of the types of more frequent imperfections, accountability of conformity it corresponded the platforms next $36 \%$ to the imperfections evidenced in the analyzed period, followed of the restriction to the efficiency of the PNAE whose index was of 33\% and the restrictions the democratic control that they had approximately corresponded $19 \%$ of the evidenced fragilities. The remaining failures mentioned restrictions on internal controls, and the results.
\end{abstract}

\section{Keywords}

Strategic management; Public programs and resources. 


\section{Introdução}

A transição para o Estado Nacional contemporâneo e a sua sustentabilidade, onde a conjuntura é representada, principalmente, por fatores críticos como: a nova economia (globalização, tecnologia e conhecimento), o neoliberalismo (desestabilização e liberação) e a nova gestão pública (eficiência, flexibilidade, resultado, aprendizado organizacional e social, controle social, responsabilidade social), impõem-se aos gestores que atuam neste Estado o uso de tecnologia de gestão mais apropriada à agregação de valor social e a redução e otimização dos recursos requeridos pelos processos responsáveis por tal agregação. Pela grande necessidade de redução e otimização (eficiência) na utilização de recursos, destaca-se a tecnologia de Gestão Estratégica de Recursos, como imprescindíveis para a administração eficiente dos programas e atividades públicas que compõem tal Estado, em especial, quanto à gestão do Programa Nacional de Alimentação Escolar, que é estudado neste trabalho.

O presente trabalho é dividido em cinco partes: na primeira, é feita a introdução do assunto, onde são contextualizados os conceitos de gestão estratégica e aprendizado no contexto das organizações públicas e definido o problema de pesquisa e objetivos da pesquisa. Na segunda parte são discutidas as teorias de sustentação deste estudo, sendo abordadas três vertentes teóricas - Nova Administração Pública; Gestão Estratégica de Recursos e Auditoria Operacional. Já na terceira parte, são apresentados os materiais e métodos da pesquisa. No tópico seguinte são apresentados e discutidos os resultados da pesquisa e, no último, são expostas as conclusões do estudo.

No Estado Brasileiro tem-se buscado, principalmente, nas duas décadas mais recentes, alternativas de modernização da gestão pública. Exemplo disso é o programa de gestão denominado GESPÚBLICA que está disponível, para uso por adesão, a qualquer unidade pública nacional, e, que cujas premissas se fundamentam em princípios constitucionais cuja essência determina: “a gestão pública para ser excelente tem que ser legal, impessoal, moral, pública e eficiente" (BRASIL, 2008, p. 10)

Além destes princípios a GESPÚBLICA se fundamenta também, nos seguintes pressupostos da excelência gerencial (BRASIL, 2008, p. 10-16):

(a) Pensamento sistêmico (entendimento das relações de interdependência entre os diversos componentes de uma organização, bem como entre a organização e o ambiente externo, com foco na sociedade); (b) Aprendizado organizacional (busca contínua e alcance de novos patamares de conhecimento, individuais e coletivos, por meio da percepção, reflexão, avaliação e compartilhamento de informações e experiências); (c) Cultura da inovação (promoção de um ambiente favorável à criatividade, à experimentação e à implementação de novas idéias que possam gerar um diferencial para a atuação da organização); (d) Liderança e constância de propósitos (a liderança é o elemento promotor da gestão, responsável pela orientação, estímulo e comprometimento para o alcance e melhoria dos resultados organizacionais, devendo atuar de forma aberta, democrática, inspiradora e motivadora das pessoas, visando o desenvolvimento da cultura da excelência, a promoção de relações de qualidade e a proteção do interesse público. É exercida pela alta administração, entendida como o mais alto nível gerencial e assessoria da organização); (e) Orientação por processos e informações (compreensão e segmentação do conjunto das atividades e processos da organização que agreguem valor para as partes interessadas, onde a tomada de decisões e a execução de ações devem ter como base a medição e análise do desempenho, levando-se em consideração as informações disponíveis); (f) Visão de futuro (indica o rumo de uma organização e a constância de propósitos que a mantém nesse rumo. Está diretamente relacionada à capacidade de estabelecer um estado futuro desejado que dê coerência ao processo decisório e permita à organização antecipar-se às necessidades e expectativas dos cidadãos e da sociedade. Inclui, também, a compreensão dos fatores externos que afetam a organização, com o objetivo de gerenciar seu impacto na sociedade); ( $\mathrm{g}$ ) Geração de valor (alcance de resultados consistentes, assegurando o aumento de valor tangível e intangível de forma sustentada para todas as partes interessadas); (h) Comprometimento com as pessoas (estabelecimento de relações com as pessoas, criando condições de melhoria da qualidade nas relações de trabalho para que elas se realizem profissional e humanamente, maximizando seu desempenho por meio do comprometimento, da oportunidade para desenvolver competências e habilidades para empreender, do incentivo e do reconhecimento); (i) Foco no cidadão e na sociedade (direcionamento das ações públicas para atender regular e continuamente as necessidades dos cidadãos e da sociedade, na condição de sujeitos de direitos, beneficiários dos serviços públicos e destinatários da ação decorrente do poder de Estado, exercido pelas organizações públicas); (j) Desenvolvimento de parcerias (desenvolvimento de atividades conjuntamente com outras organizações, com objetivos específicos comuns, buscando o pleno uso das suas competências complementares para desenvolver sinergias); ( $k$ ) Responsabilidade social (atuação voltada para assegurar às pessoas a condição de cidadania, com garantia de acesso aos bens e serviços essenciais, e ao mesmo tempo, tendo como um dos princípios gerenciais a preservação da biodiversidade e dos ecossistemas naturais, potencializando a capacidade das gerações futuras de atender suas próprias necessidades); (I) Controle Social (atuação que se define pela participação das partes interessadas no planejamento, acompanhamento e avaliação das atividades da Administração Pública e na execução das políticas e dos programas públicos); (m) Gestão participativa (estilo de gestão que implica em uma atitude gerencial da alta administração que busque o máximo de cooperação das pessoas, reconhecendo a capacidade e o potencial de cada uma e harmonizando os interesses individuais e coletivos a fim de conseguir a sinergia das equipes de trabalho). 
Tais pressupostos coadunam com a visão manifesta pelo Governo e empresários brasileiros no Plano de Ação Contra a Crise (2009, p. 30-31) no qual se afirma que o Estado deve assimilar "técnicas gerenciais contemporâneas utilizadas pela iniciativa privada (com adaptações à realidade estatal). Inclusive aplicação da metodologia de gestão PDCA (Plan, Do, Check, Act), tanto do ponto de vista estratégico como operacional".

No entanto, a implantação plena destes pressupostos depende de mudanças e adaptações culturais que, em alguns casos, demandam décadas ou até mesmo gerações para se efetivar. Enquanto isto não se efetiva, tecnologias de gestão com resultados mais imediatistas podem ser utilizadas. Este é caso, atualmente, do "movimento sobre a implantação da gestão estratégica de custos" na administração pública brasileira. Diante desta conjuntura apresenta-se no próximo subitem o problema e os objetivos da pesquisa.

\subsection{Problema e Objetivos da Pesquisa}

Em uma pesquisa recente desenvolvida pelos autores e apresentada, em parte, no tópico resultados deste trabalho, sobre o comportamento das variáveis restritivas ao sucesso dos programas federais, executados pelos municípios, frente aos princípios da nova administração pública, evidenciou-se uma série de imperícias e impropriedades que ocorreram em todo o território brasileiro, principalmente, na gestão e execução de programas sociais mantidos pelo governo nacional. Tais constatações indicam a necessidade de se desenvolver e implantar com urgência uma tecnologia de gestão estratégica de recursos com o propósito de evitar tais imperícias e impropriedades, e obviamente, melhorar o desempenho e efetividade dos programas governamentais.

Neste artigo, utilizar-se-á como unidade de análise o Programa Nacional de Alimentação Escolar - PNAE. A escolha deste programa deve-se ao montante de recursos e a abrangência do PNAE, já que segundo o Fundo Nacional de Desenvolvimento da Educação - FNDE (2010) está previsto para este programa o orçamento três bilhões para o exercício de 2010, com o objetivo de beneficiar 47 milhões de estudantes da educação básica e de jovens e adultos. Além disso, o programa tem grande relevância social, considerando que o oferecimento da alimentação escolar é importante para a qualidade do aprendizado e da manutenção do aluno na escola.

Diante do exposto, o desafio (problema) a ser trabalhado neste artigo, consiste em: Como associar a arquitetura teórica da gestão estratégica de recursos do Programa Nacional de Alimentação Escolar aos vetores de eliminação da ocorrência de variáveis restritivas ao sucesso deste programa?

Como objetivos a serem alcançados pretende-se: em geral, associar a arquitetura teórica da gestão estratégica de recursos do Programa Nacional de Alimentação Escolar com os vetores de eliminação da ocorrência de variáveis restritivas ao sucesso do programa. E, especificamente: (a) apresentar um conjunto de teorias sobre pressupostos da nova administração pública; (b) discutir a teoria da gestão estratégica de recursos, focada na arquitetura conceitual da gestão estratégica de custos ( $A B M / A B C$ ); e (c) apresentar e tratar as variáveis restritivas à efetividade do Programa de Alimentação Escolar, diante da perspectiva tecnológica da Gestão Estratégica de Recursos. Para oferecer compreensão e tratamento ao desafio descrito anteriormente, bem como para os objetivos estabelecidos, uma base teórica é apresentada no tópico a seguir.

\section{Teorias de Sustentação à Pesquisa}

As mudanças estruturais e de cultura institucional no mapa estratégico das organizações privadas tem inspirado insights e exigido adaptações também no ambiente crítico da organização pública. Por exemplo, a relação inadequada entre o sistema de liderança política e as características das decisões e das ferramentas gerenciais. Isso se torna ainda mais difícil quando se apresentam restrições como: (a) demanda crescente por serviços públicos com qualidade; (b) escassez de recursos; e, (c) conflito entre os entes (unidades) estatais do sistema federalista nacional e a sociedade. Isso conduz a uma reflexão sobre o paradigma da nova administração pública. 
Avaliação de variáveis restritivas à qualidade na execução do programa nacional de alimentação escolar com inserção à gestão estratégica de recursos públicos

\subsection{Nova Administração Pública}

Em meados da década de 1970 observou-se um movimento em todo o globo no sentido de reformar a Administração Pública para torná-la mais ágil e eficiente. Um dos primeiros países a se destacar nesse processo foi o Reino Unido, que a partir de 1979 sob o governo de Thatcher, iniciou um processo de profunda reestruturação na administração pública inglesa, com o intuito de diminuir o tamanho do Estado e torná-lo mais eficiente. (ABRUCIO, 2006; JENKINS, 2006)

Já na década de 1980 reformas semelhantes foram iniciadas na Nova Zelândia e Austrália. Em todas essas reformas foram identificadas algumas características em comum, a exemplo da utilização de instrumentos como descentralizações, privatizações, terceirizações, tendo como objetivo central o aumento da eficiência do Estado. Logo, esse movimento passou a ser denominado de Nova Administração Pública.

Para Ferlie et al (1999, p.26) não há definições uniformes e objetivas quanto ao conceito e as características da NAP, para estes autores:

[ ...] algumas vezes a nova administração pública parece uma tela vazia: pode-se pintar o que quiser nela. Não há definições claras ou unânimes sobre o que a nova administração pública é realmente e não somente há controvérsia acerca do que é ou do que está a caminho de tornar-se, mas também do que deveria ser.

Já no entendimento de Slomski et al (2008, p. 158-160) a NAP caracteriza-se pelo processo de transposição de conceitos da administração de negócios para a administração pública e se distingue das demais reformas de Estado por necessitar de mudanças legais e, na maioria dos casos, serem efetivada por um processo de transição de uma administração burocrática para a gerencial.

Para Bresser Pereira (2006) apud Ribeiro et al (2008, p.1) essa administração gerencial busca um realinhamento do Estado voltando-o para o atendimento das necessidades do cidadão e a obtenção de resultados, sendo utilizada como estratégia para atingir seus fins e incentivar a inovação, partindo-se do pressuposto de que "os políticos e funcionários são merecedores de grau limitado de confiança".

Nesse sentido, no entendimento de Ferlie et a/ (1999), corroborado por Bresser Pereira (2006), a Nova administração pública se fundamenta em pressupostos básicos para a melhoria do desempenho da administração pública, os quais se destacam: (a) preocupação com a eficiência da ação governamental; (b) orientação para obtenção de resultados; (c) foco no atendimento às necessidades dos cidadãos-usuários; (d) controle voltado para os resultados (a posterior); (e) fortalecimento do controle social; e (f) transparência e gestão responsável.

Osborne e Gaebler (1994) ao focalizarem a administração pública numa perspectiva até certo ponto revolucionária, exerceram uma grande influência para as mudanças nesta área de modo geral. Pois, eles incluíram em seus insights a necessidade do gestor público - o ente governante - ou seja, o líder principal, de se portar de acordo com as seguintes diretrizes: atuar como um governo catalisador, pertencer à comunidade, ser competitivo, orientar-se por missões, criar resultados, instruir-se pelos usuários dos seus serviços (usuário), agir como um empreendedor, ser preventivo, promover a descentralização e orientar-se para o mercado.

No Brasil, a nova administração pública teve o seu grande start com a reforma do Estado e da administração pública gerencial em 1995, com a gestão virtual que se concretiza a cada dia e com o Programa Nacional de Gestão Pública e Desburocratização - GESPÚBLICA. Essa ultima como já caracterizada anteriormente, se fundamenta em princípios constitucionais, cuja essência determina: "a gestão pública para ser excelente tem que ser legal, impessoal, moral, pública e eficiente", bem como, em um conjunto de pressupostos de excelência gerencial. Grande parte destes pressupostos é muito comum em organizações privadas, como também já deu prova de compatibilização na gestão pública, embora sejam elas de características diferentes, como mostram os dois exemplos apresentados no próximo tópico.

Segundo o documento 1 (um) - Instrumento para avaliação da gestão pública - GESPÚBLICA - Ciclo 2008/2009 (BRASIL, 2008), diversas características inerentes à natureza pública diferenciam as organizações da administração pública das organizações da iniciativa privada. Destacam-se duas delas neste trabalho como exemplo: (a) as organizações privadas buscam o lucro financeiro e formas de garantir a sustentabilidade do negócio, enquanto a administração pública busca gerar valor para a sociedade e formas de garantir o desenvolvimento sustentável, sem perder de vista a obrigação de utilizar os recursos de forma eficiente; (b) a atividade pública é financiada com recursos públicos, oriundos de contribuições compulsórias de cidadãos e empresas, os quais devem ser direcionados para a prestação de serviços 
públicos e a produção do bem comum; enquanto a atividade privada é financiada com recursos de particulares que têm legítimos interesses capitalistas.

Em uma análise comparativa e comportamental feita em 2007, pelo Grupo de Estudos e Pesquisas em Organizações (GEPORG) da UNIR/RO, chegou-se ao entendimento de que os pressupostos da excelência gerencial reservam mais afinidade com as características da organização pública do que com a organização privada. Pois, enquanto a organização privada almeja resultado financeiro e sustentabilidade do negócio, a organização pública almeja resultado social - gerar valor para a sociedade e garantir o desenvolvimento sustentável, utilizando recursos com eficiência. Referindo-se ao uso eficiente de recursos, apresentam no próximo subitem, aspectos teóricos da gestão estratégica de recursos.

\subsection{Gestão estratégica de recursos}

Referindo-se à gestão estratégia de custos, Shank e Govindarajan (1997, p. 4-5) dizem que "ela vai muito além de um processo de avaliação do impacto financeiro das decisões gerenciais alternativas". Para estes autores a gestão estratégica de custos:

existe para facilitar a administração geral da organização, que é um processo cíclico contínuo de: (a) formar estratégia; (b) comunicar esta estratégia por toda a organização; (c) desenvolver e por em prática táticas para implantar as estratégias, e (d) desenvolver e implantar controles para monitorar as etapas da implementação e depois o sucesso no alcance das metas estratégicas (SHANK E GOVINDARAJAN, 1997, p. 5).

Considerando, portanto: (a) Gestão como ações empreendidas na criação, comunicação, implementação e controle da estratégia de uma organização; (b) a estratégia como um conjunto de hipóteses de causa e efeito para o alinhamento e empreendimento de ações orientadas para a consecução da estratégia e dos resultados objetivados; e (c) recursos como um conjunto de insumos a serem utilizados nas atividades de uma organização; pode-se caracterizar gestão estratégica de recursos como: ações empreendidas na criação, comunicação, implementação e controle das causas e efeitos objetivados de uma organização, programa, projeto ou atividade mediante a utilização de insumos.

Sobre a tecnologia para viabilizar a gestão estratégica de recursos [ custos] na organização, a que mais facilita a análise e visibilidade de eficiência e propósito é a tecnologia, Activity Based Management / Activity Based Costing (ABM/ABC). Segundo Kaplan e Cooper (1998, p. 260):

a associação de despesas organizacionais relacionadas às capacidades de suprimento de recursos às atividades executadas, e em seguida, às demandas por produtos/serviços ou clientes/usuárias específicos facilitará as decisões sobre o suprimento adequado de recursos.

Para Kaplan e Cooper (1998, p. 260) as "organizações de serviços normalmente orçam e administram seus recursos por centro de responsabilidade", assim, esses autores enfatizam que:

sem um modelo $A B C$ os gerentes de organizações de serviços não têm como associar decisões de orçamento que autorizam o suprimento de recursos para os centros de responsabilidade específicos às demandas de serviços e clientes para as atividades e serviços prestados por estes centros de responsabilidade (KAPLAN E COOPER, 1998, p. 260).

Nesse sentido, Kaplan e Cooper (1998, p. 260) destacam que os "gerentes precisam definir orçamentos em negociações anuais entre os chefes dos centros de responsabilidade e a equipe executiva sênior e que um modelo $A B C$, pode ser usado como base para o processo de orçamento de uma organização". Assim, as decisões que autorizam gastos nos centros de responsabilidade são associadas à produção dessas unidades requeridas pela potencial demanda.

Quanto às características gerais dos recursos públicos a serem gerenciados com o método ABC, são: (a) pessoal; (b) materiais de consumo; e (c) serviços de terceiros. Para Alonso (1998, p. 19) algumas das vantagens que a utilização do método $A B C$ representa para gerenciamento dos recursos governamentais são:

(a) melhorar o desempenho das organizações públicas; (b) mostra as causas do mau desempenho; (c) parametriza a função alocativa de governo, gerando indicadores de eficiência e eficácia; (d) ênfase nos resultados e nos custos; (e) influencia o comportamento dos gestores governamentais; e (f) accountability: responsabiliza pessoalmente os gestores/dirigentes; [ dentre outras]. 
Para associar a metodologia $\mathrm{ABC}$ à gestão estratégica de programas governamentais é conveniente associar também, alguns conceitos relacionados à avaliação de programas, que no contexto deste estudo, será analisado como integrante da atividade de auditoria operacional.

De acordo com o United States Government Accountability Office - GAO (2005) a avaliação de programas constitui-se em uma das classificações da auditoria operacional, já que essa atividade:

implicam exame objetivo e sistemático da evidência para apresentar uma avaliação independente do desempenho e da gestão de um programa com base em critérios objetivos, assim como avaliações que proporcionem um enfoque prospectivo ou que sintetizam sobre as melhores práticas ou análise de temas transversais. (GAO, 2005, p. 32 e 45).

Segundo o GAO (2005), este tipo de auditoria pode ter geralmente cinco objetivos: efetividade/resultado, economicidade/eficiência, controle interno, conformidade com as normas e análise prospectiva. A Figura 1 apresentada a seguir oferece uma compreensão coletiva destes objetivos.

Figura 1 - Fluxograma de objetivos da auditoria operacional.

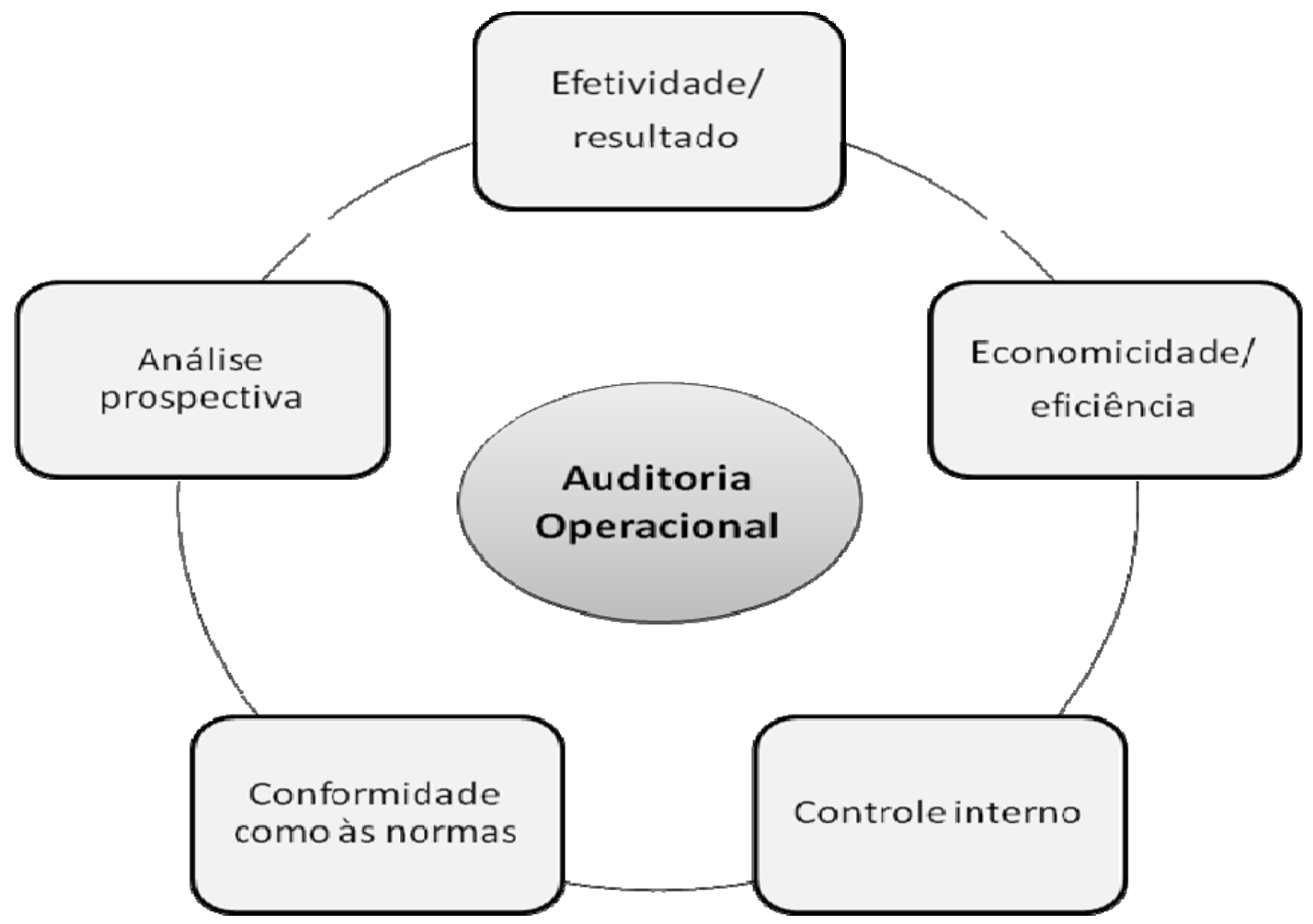

Fonte: Elaborado a partir dos conceitos de GAO (2005).

Assim como estes princípios do GAO (2005), as demais teorias apresentadas integrarão o instrumento teórico - Instrumento conceitual de caracterização das variáveis restritivas.

\section{Material e Métodos}

O Programa Nacional de Alimentação Escolar (PNAE) foi implantado em 1955 e procura garantir, por meio da transferência de recursos financeiros, a alimentação escolar dos alunos de toda a educação básica (educação infantil, ensino fundamental, ensino médio e educação de jovens e adultos), matriculados em escolas públicas e filantrópicas. Assim, seu objetivo é:

contribuir para o crescimento e o desenvolvimento biopsicossocial, a aprendizagem, o rendimento escolar e a formação de práticas alimentares saudáveis dos alunos, por meio de ações de educação alimentar e nutricional e da oferta de refeições que cubram as suas necessidades nutricionais durante o período letivo (MEC, 2009, p. 3). 
Contudo, o PNAE tem caráter suplementar, ou seja, o valor repassado pelo Governo Federal deve ser complementado pelos governantes dos Estados e Municípios. Atualmente, o valor repassado pela União, por dia letivo, é de $\mathrm{R} \$ 0,30$ por aluno. Enquanto, para estudantes das escolas indígenas e localizadas em comunidades quilombolas, esse o valor é de $\mathrm{R} \$ 0,60$. Os recursos destinam-se à compra de alimentos pelas secretarias de Educação dos estados e do Distrito Federal e pelos municípios, sendo sua aplicação acompanhada e fiscalizada diretamente pela sociedade, por meio dos Conselhos de Alimentação Escolar (CAEs), pelo Tribunal de Contas da União (TCU), pela CGU e pelo Ministério Público (FNDE, 2010).

\subsection{Material}

O material da pesquisa consiste nos relatórios produzidos pela CGU (ver Quadro 2), provenientes de auditorias realizadas para avaliar a execução dos programas governamentais federais pelos municípios brasileiros. Estes relatórios são restritivos, ou seja, somente identificam as falhas evidenciadas na execução do programa em cada município auditado, contudo, não são emitidas recomendações para saná-las.

\subsection{Instrumento Teórico}

O instrumento teórico apresentado a seguir (Quadro 1) tem como objetivo apresentar suporte conceitual à análise dos relatórios de fiscalizações emitidos pela CGU. Este instrumento é composto por seis categorias que foram criadas a partir de conceitos extraídos dos objetivos das auditorias operacionais referenciadas pelo GAO (2005) e de controle democrático, descrito por Bresser Pereira (1998).

Quadro 1 - Instrumento conceitual de caracterização das variáveis.

\begin{tabular}{|c|c|c|c|}
\hline \multirow[b]{2}{*}{$\begin{array}{c}\text { PRINCÍPIOS DA NAP } \\
\text { (1) }\end{array}$} & \multirow{2}{*}{$\begin{array}{c}\text { CATEGORIAS DE ATRIBUTOS DA } \\
\text { AVAL LACAAODE ROGRAMAS } \\
\text { CONFORME NAP (2) }\end{array}$} & \multicolumn{2}{|r|}{ SUBCATEGORIAS (3) } \\
\hline & & $\begin{array}{c}\text { FOCO DA } \\
\text { AVALAÇÃO/ } \\
\text { AUDITAGEM (3a) }\end{array}$ & $\begin{array}{c}\text { VARIÁVEIS RESTRITIVAS } \\
\text { (VÉSAO FOCO) } \\
\text { (3b) }\end{array}$ \\
\hline \multirow{2}{*}{$\begin{array}{l}\text { Feedback d̀s necessidades } \\
\text { dos cidadãos-usuários } \\
\text { (OSBORNE e GAEBLER, } \\
\text { 1998, p.181) } \\
\text { Orientação para o resultado. } \\
\text { (BRESSER PEREIRA 2006, p. } \\
\text { 28) } \\
\text { Controle de resultado (a } \\
\text { posteriori) (BRESSER } \\
\text { PEREIRA 2006, p. 243) }\end{array}$} & \multirow{2}{*}{$\begin{array}{c}\text { Resultados } \\
\text { Identifica aspectos relacionados ao } \\
\text { alcance das metas e objetivos dos } \\
\text { programas, bem como quanto ao seu } \\
\text { efetivo impacto na sociedade. } \\
\text { (GAO, 2005, p. 46) }\end{array}$} & $\begin{array}{c}\text { Efetividade } \\
\text { (Barzelay, 2002, p. } \\
\text { 19) }\end{array}$ & $\begin{array}{l}\text { Refere-se a fatos evidenciados nos relatórios de que } \\
\text { o programa não está produzindo os efeitos } \\
\text { esperados, ou seja, não está contribuindo para a } \\
\text { diminuição ou eliminação do problema social que o } \\
\text { originou. }\end{array}$ \\
\hline & & $\begin{array}{c}\text { Eficácia } \\
(\mathrm{GAO}, 2005, \mathrm{p} .46- \\
7)\end{array}$ & $\begin{array}{l}\text { Relaciona-se a fatos evidenciados nos relatónios } \\
\text { sobre: } \\
\text { - o não alcance ou alcance parcial das metas e } \\
\text { objetivos dos programas; } \\
\text { - fatores que inibam o cumprimento dos objetivos } \\
\text { dos programas. }\end{array}$ \\
\hline \multirow{3}{*}{$\begin{array}{l}\text { Orientação para o resultado. } \\
\text { (BRESSER PEREIRA 2006, } p \text {. } \\
\text { 28) } \\
\text { Impulso para a eficiência. } \\
\text { (FERLIE ET AL, 1999, p. 27) } \\
\text { Aumento da produtividade. } \\
\text { (ABRUCIO, 2006, p. 182) } \\
\text { Controle de resultado (a } \\
\text { posteriori) } \\
\text { (BRESSER PEREIRA 2006, } p \text {. } \\
\text { 243). }\end{array}$} & \multirow{3}{*}{$\begin{array}{c}\text { Eficiência } \\
\text { dentifica fatores relacionados à } \\
\text { uisição, proteção e utilização dos } \\
\text { cursos de forma produtiva para o } \\
\text { cance dos objetivos do programa. } \\
(G A O, 2005, p .46)\end{array}$} & $\begin{array}{l}\text { Uso adequado do } \\
\text { recurso } \\
(\mathrm{GAO}, 2005, \mathrm{p} .46- \\
7)\end{array}$ & $\begin{array}{l}\text { Refere-se a fatos evidenciados nos relatórios sobre: } \\
\text { - a execução de ações do programa em } \\
\text { duplicidade; } \\
\text { - a falta de utilização de recursos financeiros do } \\
\text { programa por período superior a seis meses. } \\
\text { - o pagamento por serviços não prestado ou } \\
\text { produtos não entregues. } \\
\text { - a utilização em excesso de recursos para o } \\
\text { alcance dos objetivos definidos. } \\
\text { - a falta de aplicação dos recursos do programa no } \\
\text { mercado financeiro. }\end{array}$ \\
\hline & & $\begin{array}{l}\text { Objetivo-meio } \\
\text { (INTOSAl, 2005, p. } \\
\text { 103) }\end{array}$ & $\begin{array}{l}\text { Relaciona-se a fatos evidenciados nos relatónios } \\
\text { sobre a utilização de recursos do programa } \\
\text { (financeiros, humanos e materiais) em ações não } \\
\text { previstas ou incoerentes com seus objetivos. }\end{array}$ \\
\hline & & $\begin{array}{c}\text { Economicidade } \\
(\mathrm{GAO}, 2005, \text { p. 47) }\end{array}$ & $\begin{array}{l}\text { Refere-se a fatos evidenciados nos relatórios sobre } \\
\text { prática imprópria de aquisição de insumos para o } \\
\text { programa: preço, quantidade ou qualidade } \\
\text { inadequados. }\end{array}$ \\
\hline
\end{tabular}

Continua... 


\section{Continuação...}

\begin{tabular}{|c|c|c|c|}
\hline \multirow[b]{2}{*}{ 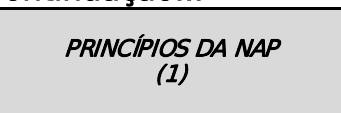 } & \multirow[b]{2}{*}{$\begin{array}{c}\text { CATEGORLAS DE ATRIBUTOS DA } \\
\text { AVALIAÇAO DE ROGRAMAS CONFORME } \\
\text { NAP (2) }\end{array}$} & \multicolumn{2}{|r|}{ SUBCATEGORIAS (3) } \\
\hline & & $\begin{array}{c}\text { FOCO DA } \\
\text { AVALACÃO/ } \\
\text { AUDITAGEM (3a) }\end{array}$ & $\begin{array}{c}\text { VARIAVEIS RESTRITIVAS } \\
\text { (VESS AO FOCO) } \\
(3 b)\end{array}$ \\
\hline \multirow{2}{*}{$\begin{array}{l}\text { Orientação para o resultado. } \\
\text { (BRESSER PEREIRA 2006, } p . \\
\text { 28) } \\
\text { Accountability } \\
\text { (ABRUCIO, 2006, p. 190; } \\
\text { BRESSER PEREIRA, 1998, p. } \\
\text { 142) } \\
\text { Impulso para a eficiência. } \\
\text { (FERLIE ET AL, 1999, p. 27) }\end{array}$} & \multirow{2}{*}{$\begin{array}{c}\text { Controle interno } \\
\text { Identifica aspectos relacionados aos } \\
\text { planos, métodos e procedimentos } \\
\text { utilizados pela Administração para cumprir } \\
\text { sua missão, objetivos e metas. } \\
\text { (GAO, 2005, p. 48) }\end{array}$} & $\begin{array}{l}\text { Fidedignidade dos } \\
\text { documentos } \\
(\mathrm{GAO}, 2005, \text { p. 48) }\end{array}$ & $\begin{array}{l}\text { Refere-se a fatos evidenciados nos relatórios } \\
\text { sobre a existência de documentos } \\
\text { (incompletos, inconsistentes e } \\
\text { desatualizados) gerados pelo programa }\end{array}$ \\
\hline & & $\begin{array}{c}\text { Controles } \\
\text { administrativos } \\
(\mathrm{GAO}, 2005, \mathrm{p} .48)\end{array}$ & $\begin{array}{l}\text { Relaciona-se a fatos evidenciados nos } \\
\text { relatórios sobre: } \\
\text { - a inexistência ou inadequação dos } \\
\text { mecanismos de controles das operações do } \\
\text { programa; } \\
\text { - a ausência de mecan ismos de proteção } \\
\text { dos recursos do programa contra aquisições, } \\
\text { utilizações ou distribuições não autorizadas. }\end{array}$ \\
\hline $\begin{array}{l}\text { Accountability. } \\
\text { (ABRUCIO, 2006, p. 190; } \\
\text { BRESSER PEREIRA, 1998, p. } \\
\text { 142) }\end{array}$ & $\begin{array}{c}\text { Conformidade com as normas } \\
\text { Identifica aspectos relacionados à } \\
\text { conformidade das açóes do programa com } \\
\text { as exigências estabelecidas por leis, } \\
\text { regulamentos, contrato e convênios. } \\
(\mathrm{GAO}, 2005, \mathrm{p} .49)\end{array}$ & $\begin{array}{l}\text { Accountability de } \\
\text { conformidade } \\
\text { (Barzelay, 2002, p. } \\
\text { 8) }\end{array}$ & $\begin{array}{l}\text { Refere-se a fatos evidenciados nos relatórios } \\
\text { quanto ao descumprimento de normas que } \\
\text { regulamentam as ações do programa. }\end{array}$ \\
\hline \multirow[b]{2}{*}{$\begin{array}{l}\text { ACcountability. } \\
\text { (ABRUCIO, 2006, p. 190; } \\
\text { KETIL, 2006, 2006, p. 116) } \\
\text { Feedback às necessidades } \\
\text { dos cidadãos-Usuários. } \\
\text { (OSBORNE e GAEBLER, 1998, } \\
\text { p. 181) } \\
\text { Fortalecimento do controle } \\
\text { social. } \\
\text { (BRESSER PEREIRA 2006, p. } \\
\text { 243) } \\
\text { Participação do cidadão nas } \\
\text { decisóes públicas. } \\
\text { (OSBORNE e GAEBLER, 1998, } \\
\text { p. 181) } \\
\text { Transparência. } \\
\text { (ABRUCIO, 2006, p. 190) }\end{array}$} & \multirow[b]{2}{*}{$\begin{array}{c}\text { Controle democrático } \\
\text { Identifica aspectos relacionados à } \\
\text { transparência na gestão dos programas e } \\
\text { ao funcionamento dos mecanismos de } \\
\text { controle social. } \\
\text { (BRESSER PEREIRA, p. 140) }\end{array}$} & $\begin{array}{l}\text { Transparência } \\
\text { (BRESSER } \\
\text { PERE/RA, 1998, p. } \\
\text { 146) }\end{array}$ & $\begin{array}{l}\text { Relaciona-se a fatos evidenciados nos } \\
\text { relatórios sobre a falta de transparência nos } \\
\text { atos do programa. }\end{array}$ \\
\hline & & $\begin{array}{l}\text { Controle social } \\
\text { (BRESSER } \\
\text { PEREIRA, 1998, p. } \\
\text { 146) }\end{array}$ & $\begin{array}{l}\text { Referem-se a fatos evidenciados nos } \\
\text { relatórios sobre as fragilidades existentes na } \\
\text { atuação dos conselhos municipais de políticas } \\
\text { públicas, tais como: } \\
\text { - a ausência de conselhos municipais de } \\
\text { políticas públicas, quando exigidos pelos } \\
\text { normativos do programa; } \\
\text { - falta de representatividade da sociedade } \\
\text { nos conselhos; } \\
\text { - falta de atuação efetiva dos conselhos; } \\
\text { - existência de restrições à independência e } \\
\text { atuação dos conselhos. }\end{array}$ \\
\hline $\begin{array}{l}\text { Orientação para o resultado. } \\
\text { (BRESSER PEREIRA 2006, } p \text {. } \\
\text { 28) } \\
\text { Controle de resultado (a } \\
\text { posteriori) } \\
\text { (BRESSER PEREIRA } 2006, p \text {. } \\
243 \text { ) }\end{array}$ & $\begin{array}{c}\text { Análises prospectivas } \\
\text { Identifica a existência de recomendações } \\
\text { gerenciais que objetivem aperfeiçaar a } \\
\text { gestão e a melhoria nos seus resultados. } \\
\text { (GAO, 2005, p. 49) }\end{array}$ & $\begin{array}{c}\text { Recomendações } \\
\text { gerenciais } \\
(\text { GAO, 2005, p. 218) }\end{array}$ & $\begin{array}{l}\text { Refere-se a fatos evidenciados nos relatórios } \\
\text { quanto à emissão de recomendações: } \\
\text { - antieconômicas, àquelas cujos custos } \\
\text { superem os resultados esperados; } \\
\text { - ineficazes, a quais não focalizam a } \\
\text { superação das fragilidades identificadas; } \\
\text { - inapropriadas, que não sejam adequadas } \\
\text { à realidade do programa. }\end{array}$ \\
\hline
\end{tabular}

Este instrumento conceitual de caracterização das variáveis constitui-se em alicerce para aplicação do instrumento apresentado a seguir.

\subsection{Instrumento Metodológico de Tratamento dos Dados}

Para identificar e interpretar os dados coletados dos relatórios, foi utilizada a técnica de análise de conteúdo, já que para Bardin (2004, p. 27) esta técnica é a mais indicada para a análise de comunicações, sejam elas escritas ou orais. Os dados coletados receberam tratamento qualiquantitativo, sendo a análise operacionalizada mediante a classificação destes dados em seis categorias previamente definidas, seguida da utilização da estatística descritiva, em especial da freqüência, para a análise e apresentação dos resultados.

\subsection{Universo e Amostra}

Estabeleceu-se dois critérios para a definição do universo da pesquisa, o primeiro é temporal, sendo estabelecidos os relatórios referentes às auditorias realizadas nos anos de 2005 a 2007; enquanto o segundo é a sua disponibilidade no sítio eletrônico da CGU. Atendendo a esses requisitos, identificou-se 600 (seiscentos) relatórios. Para a definição da amostra, adotou-se o nível de confiança de $90 \%$ (noventa por cento) e uma margem de erro de $5 \%$ (cinco por cento), que após os arredondamentos efetuados na estratificação da amostragem conduziu a definição do quantitativo de 197 (cento e noventa e sete) relatórios como amostra desta pesquisa. A fim de possibilitar a análise temporal do comportamento de cada categoria nas cinco regiões geográficas, dividiu-se a amostra calculada de forma proporcional a 
quantidade de municípios, sorteados em cada região/estado, conforme Quadro 2 apresentado na página seguinte.

Quadro 2 - Universo e amostra da pesquisa

\begin{tabular}{|l|c|c|c|c|c|c|c|c|}
\multirow{2}{*}{ REGIÃO } & \multicolumn{2}{|c|}{2005} & \multicolumn{2}{c|}{2006} & \multicolumn{2}{c|}{2007} & \multicolumn{2}{c|}{ TOTAL } \\
\cline { 2 - 10 } & Universo & Amostra & Universo & Amostra & Universo & Amostra & Universo & Amostra \\
\hline NORTZ & $\mathbf{3 5}$ & $\mathbf{1 2}$ & $\mathbf{2 1}$ & $\mathbf{7}$ & $\mathbf{1 4}$ & $\mathbf{5}$ & $\mathbf{7 0}$ & $\mathbf{2 4}$ \\
\hline NORDESTI & $\mathbf{9 5}$ & $\mathbf{3 0}$ & $\mathbf{5 7}$ & $\mathbf{1 9}$ & $\mathbf{5 2}$ & $\mathbf{1 7}$ & $\mathbf{2 0 4}$ & $\mathbf{6 6}$ \\
\hline SUDRSTR & $\mathbf{8 0}$ & $\mathbf{2 6}$ & $\mathbf{4 8}$ & $\mathbf{1 6}$ & $\mathbf{2 8}$ & $\mathbf{9}$ & $\mathbf{1 5 6}$ & $\mathbf{5 1}$ \\
\hline SUL & $\mathbf{6 0}$ & $\mathbf{1 9}$ & $\mathbf{3 6}$ & $\mathbf{1 2}$ & $\mathbf{1 8}$ & $\mathbf{6}$ & $\mathbf{1 1 4}$ & $\mathbf{3 7}$ \\
\hline CENTRO & $\mathbf{3 0}$ & $\mathbf{1 0}$ & $\mathbf{1 8}$ & $\mathbf{6}$ & $\mathbf{8}$ & $\mathbf{3}$ & $\mathbf{5 6}$ & $\mathbf{1 9}$ \\
\hline TOTAL & $\mathbf{3 0 0}$ & $\mathbf{9 7}$ & $\mathbf{1 8 0}$ & $\mathbf{6 0}$ & $\mathbf{1 2 0}$ & $\mathbf{4 0}$ & $\mathbf{6 0 0}$ & $\mathbf{1 9 7}$ \\
\hline
\end{tabular}

Dessa forma, procurou-se garantir que o número de relatórios analisados fosse representativo da quantidade de relatórios produzido para cada estado/região. Com base neste quantitativo, foi efetuada, de forma aleatória, a escolha dos municípios cujos relatórios compõem o corpus desta pesquisa. Nesta operação foi utilizada a Ferramenta Amostragem do Suplemento Analise de Dados do Programa Excel.

\section{Resultados e Discussões}

Por meio da análise destes documentos foram catalogadas 7.841 (sete mil, oitocentas e quarenta e uma) falhas identificadas na execução de programas ligados ao Ministério da Educação, ao Ministério do Desenvolvimento Social e Combate à Fome e ao Ministério da Saúde. Desse total, 793 (setecentos e noventa e três) falhas são relacionadas a fragilidades evidenciadas pela CGU na execução do PNAE nos municípios pesquisados.

O resultado dessa análise permitiu evidenciar a existência de variáveis restritivas à qualidade da gestão do Programa Nacional de Alimentação Escolar em 89\% (oitenta e nove por cento) dos municípios auditados pela Controladoria Geral da UNIÃO, sendo que, o tipo de falha mais frequente refere-se ao descumprimento das normas aplicáveis ao programa (accountability de conformidade), conforme Gráfico 1.

Gráfico 1 - Gráfico sobre as variáveis restritivas à efetividade do Programa Nacional de Alimentação Escolar

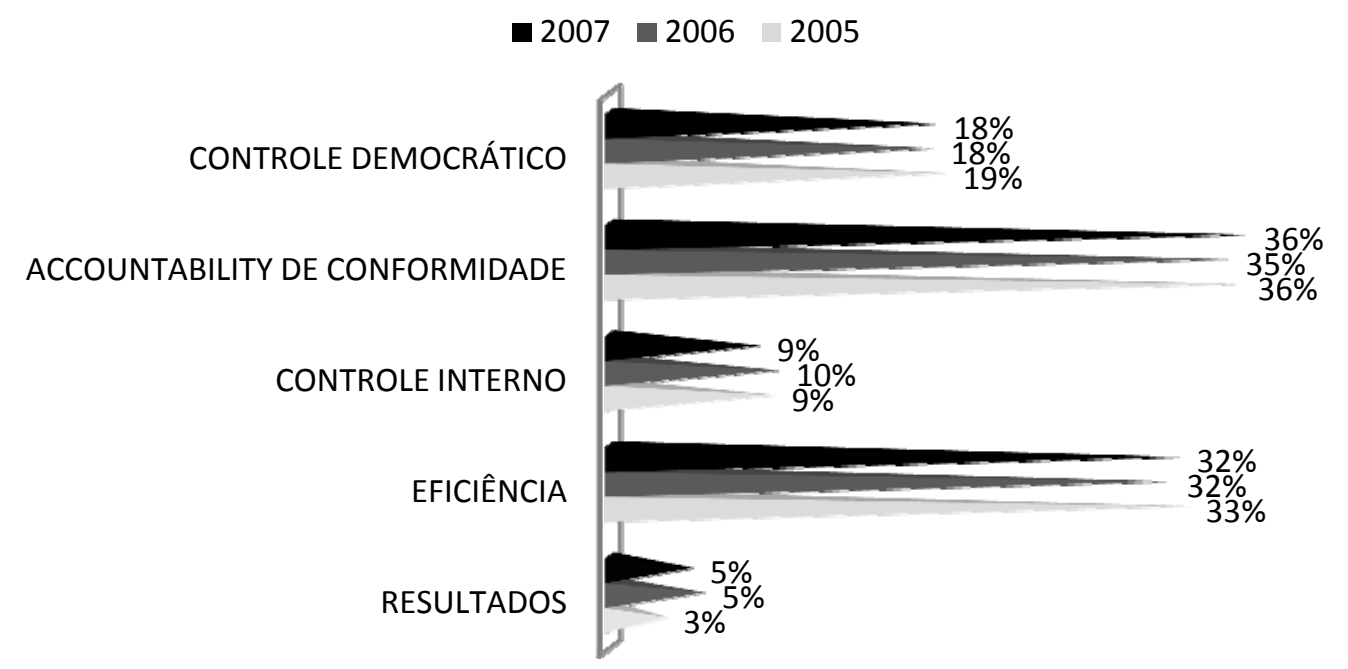

As informações expostas no Gráfico 1 se referem à frequência de falhas classificadas em cada categoria, considerando o total de variáveis restritivas evidenciadas nos relatórios analisados. Da análise destas informações evidencia-se que restrição à accountability de conformidade correspondeu a $36 \%$ das falhas evidenciadas em 2005, tendo uma pequena redução no ano seguinte (35\%) e voltando ao percentual de $36 \%$ em 2007. Erro mais comum identificado nos relatórios foi, entre outros, o não cumprimento integral de responsabilidades que os gestores do Programa tinham pactuados perante as normas existentes, a exemplo do regulamento de compras do setor públicos; das normas ligadas à execução orçamentária dos recursos, bem como, de normas específicas de funcionamento do programa. 
Quanto às restrições a eficiência, evidenciou-se que as falhas mais freqüentes referiram-se à: (a) compra de alimentos em valores superiores aos preços do mercado local (superfaturamento); (b) utilização dos recursos em atividades não ligadas à alimentação escolar; (c) armazenamento e condições inadequadas de preparo da merenda escolar; (d) falta de nutricionista e elaboração de cardápio para o preparo da alimentação. Tais falhas impactam diretamente na qualidade da execução do programa, à medida que evidencia nos municípios em que este tipo de falha é presente que parte dos recursos do programa são direcionados às atividades que não agregam valor social, em específico, no caso do superfaturamento, algum dos partícipes da execução do programa (fornecedores e/ou agentes públicos) acabam recebendo indevidamente parte desses recursos. Como conseqüência, uma quantidade menor de produtos é adquirida, o que implica no oferecimento de menos alimentos aos beneficiários do programa.

Enquanto, em relação às restrições ao controle democrático, as falhas mais constantes identificadas nas auditorias são relacionados à falta de divulgação aos partidos políticos, sindicatos e entidades empresariais, sobre o recebimento de recursos financeiros do programa e às fragilidades na atuação do Conselho de Alimentação Escolar (CAE). Esse aspecto denota as limitações existentes nos mecanismos de controle social do PNAE, já que o canal formal de participação da sociedade é que o CAE apresenta, em parte dos municípios auditados, limitações que impossibilitam que esse órgão possa desenvolver adequadamente suas atribuições, como por exemplo: ausência de infraestrutura necessária e de qualificação para que os membros dos conselhos possam exercer suas atribuições adequadamente e composição não paritária dos conselhos (governo/sociedade) dos conselhos.

Já em relação à restrição aos controles internos, evidenciou-se ser mais freqüente a ausência de mecanismos de controles quanto ao armazenamento e distribuição dos alimentos destinados à merenda escolar. Por último, as restrições aos resultados evidenciados nos relatórios referem-se à falta de oferecimento de alimentação escolar aos estudantes beneficiários do programa. Embora examinado nos relatórios pesquisados, não foram identificadas restrições à categoria análise prospectiva, este resultado deve-se ao fato dos relatórios de auditoria analisados não indicarem recomendações visando o aperfeiçoamento dos programas avaliados.

\section{Arquitetura é Gestão Estratégica de Recursos (Desempenho): orientação ao programa de alimentação escolar}

Igualmente aos outros programas sociais do governo federal o Programa Nacional de Alimentação Escolar também se enquadra no que se pode classificar de uma combinação de altos custos, qualidade inconsistente e erros freqüentes. Esta combinação indesejada, vai além dos elementos descritos, pois, há uma grande soma de recursos públicos alocados nestes programas, parte não chega às atividades do sistema de execução, e da parcela que chega, parte é perdida com imperícias e desperdícios, como verificado na pesquisa apresentada no Gráfico, deste trabalho.

Nesse sentido e para contribuir na redução de tal combinação indesejada, principalmente naquilo que diz respeito às imperícias e desperdícios de recursos, apresenta-se a seguir, na Figura 2, um modelo com o propósito de orientar o processo de orçamento e obviamente, a melhoria contínua de desempenho na aplicação de recursos em programas como, por exemplo, o Programa Nacional de Alimentação Escolar.

A lógica do modelo converge para aquilo que as novas teorias da administração pública apresentam como paradigma gerencial, ou seja, no programa público, o orçamento dos recursos a ser utilizado no cumprimento das suas demandas é obrigatório, porém, se este orçamento for elaborado com bases em atividades, favorecerá a mensuração do desempenho (consumo de recursos, custos etc.) também baseado em atividades. Dentre as principais demandas estão: serviços, atividades e recursos.

Quanto à demanda de serviços, observa-se que para orçar e mensurar o desempenho de serviços/produtos demandados pelo Programa Nacional de Alimentação Escolar há necessidade de primeiramente, identificar quantitativo e qualitativamente os serviços a serem oferecidos, onde e quando oferecer. Este é o passo inicial, ou seja, primeiro identifique a demanda social por serviços.

Quanto à demanda de atividades, uma vez sabendo-se quais e quantos serviços se devem prestar, pode-se orçar quantitativa e qualitativamente o número de atividades compatíveis. No caso do Programa Nacional de Alimentação Escolar, as principais atividades são: quantificação da demanda, análise de cardápios (pelas nutricionistas), compras e abastecimentos às escolas, preparação e fornecimento da alimentação aos estudantes. 
Figura 2 - Fluxograma à orientação da gestão estratégia de recursos e desempenho do Programa Nacional de Alimentação Escolar.

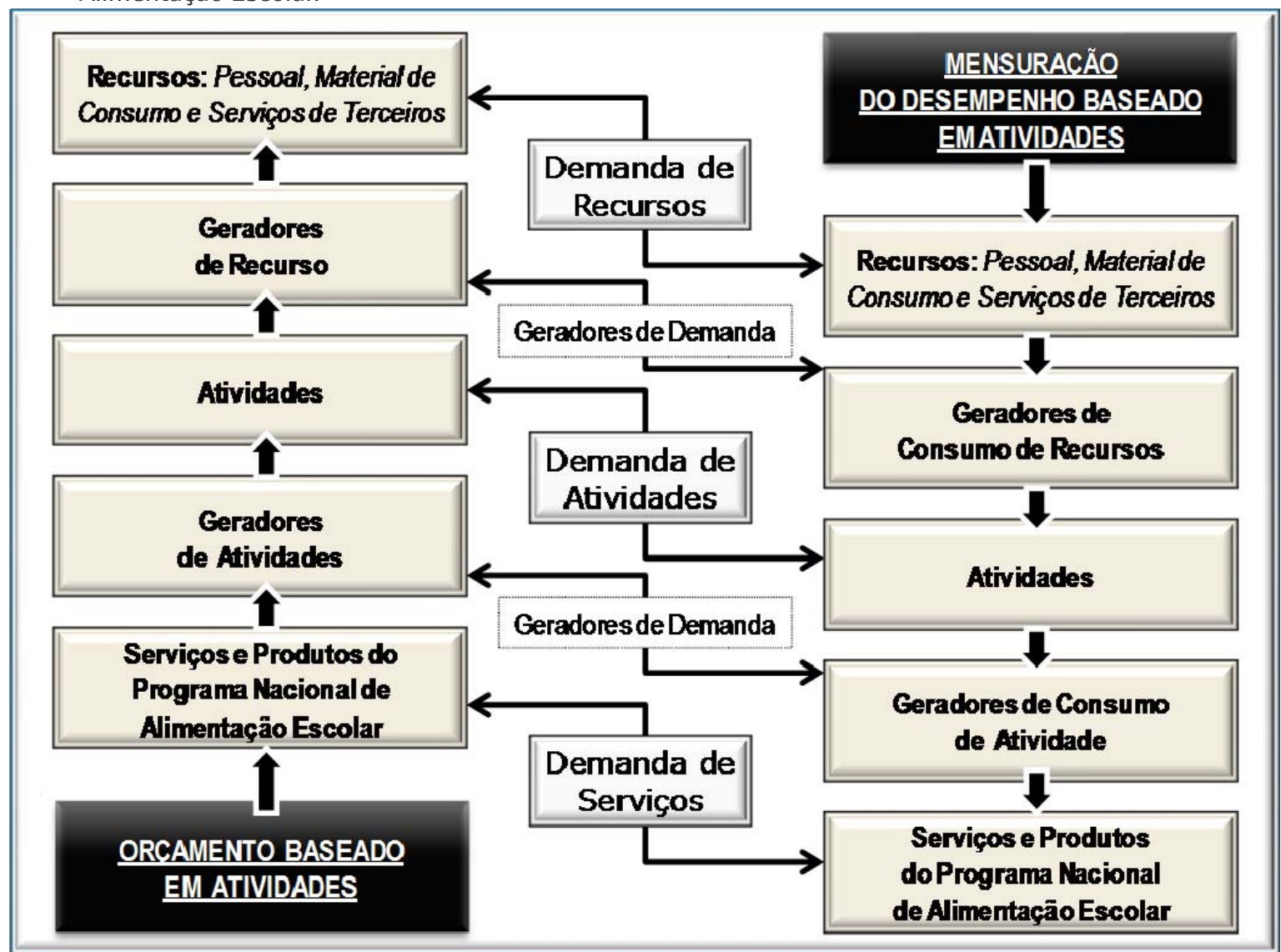

Fonte: Modelo adaptado a partir dos conceitos de Kaplan e Cooper (1998, p. 327-328)

A demanda de recursos implica no dimensionamento dos principais recursos a serem orçados. Eles são compostos por: pessoal (mão de obra), materiais de consumo/manutenção e serviços prestados por terceiros.

Quanto à mensuração do desempenho baseado em atividade, sobre o item consumo de recursos, a metodologia apresentada na llustração 5, oferece por meio dos geradores de consumo de recursos, a identificação e separação imediata das variáveis restritivas, referentes aos atos antiéticos de superfaturamento, desvios de unidades, falta de qualidade, ineficiência etc. E, quanto à mensuração do desempenho das atividades, a metodologia também oferece, por meios dos geradores de consumo de atividades, a identificação e separação das imperícias e desperdícios havidos nas atividades. Com isso, a metodologia (Figura 2) possibilita demonstrar por meio do orçamento e da mensuração do desempenho, os serviços prestados sem as indesejáveis variáveis restritivas à efetividade do Programa Nacional de Alimentação Escolar, ou de maneira contínua, contribuindo para a diminuição do que se chamou anteriormente de "combinação de altos custos, qualidade inconsistente, erros freqüentes e limitação de atendimento".

\section{Conclusão}

Embora se tenha verificado nesta pesquisa que o Brasil dispõe de metodologia de gestão contemporânea com correspondência tecnológica, estratégica e de aprendizagem com as boas metodologias internacionais, ainda não se consegue evitar a ocorrência de variáveis restritivas à efetividade de programas públicos com a dimensão social, por exemplo, do Programa Nacional de Alimentação Escolar. 
Os resultados evidenciados mostraram que as extensões da combinação de qualidade inconsistente e de erros freqüentes - excesso de variáveis restritivas à efetividade de programas público-sociais continua ocorrendo, mesmo já contando com tecnologias de gestão ágeis e conceitualmente contemporâneas.

Verificou-se, ainda, com a lógica conceitual da metodologia $\mathrm{ABC}$, que foi razoável adaptar uma metodologia orientada para a gestão estratégica de recursos (desempenho) de programas públicos. Na metodologia proposta, ao contemplar o orçamento e mensuração do desempenho, é possível responder ao desafio da pesquisa que, consistia em associar a arquitetura teórica da gestão estratégica de recursos do Programa Nacional de Alimentação Escolar com os vetores de eliminação da ocorrência de variáveis restritivas ao sucesso deste programa.

Como também foi possível alcançar o propósito deste artigo, cujo aspecto geral era associar a arquitetura teórica da gestão estratégica de recursos (ou de desempenho) do Programa Nacional de Alimentação Escolar com os vetores de eliminação da ocorrência de variáveis restritivas ao sucesso do programa.

\section{Referências}

ALONSO, M. Custo no serviço público: texto para discussão. Brasília, ENAP, 1998.

ABRUCIO, F. L. Os avanços e os dilemas do modelo pós-burocrático: a reforma da administração pública à luz da experiência internacional recente. In: PEREIRA, L. C. B.; SPINK, P. Reforma do Estado e administração pública gerencial. 7· ed. Rio de Janeiro: FGV, 2006.

BARDIN, L. Análise de conteúdo. 3. ed. Edições 70, 2004.

BARZELAY, M. Instituições centrais de auditoria e auditoria de desempenho: uma análise comparativa das estratégias organizacionais na OCDE. Revista do Serviço Público, a. 53, n. 2, abr./jun., p. 5-35, 2002.

BRASIL. Ministério do Planejamento, Orçamento e Gestão. Instruções para Avaliação da Gestão Pública 2008/2009. Brasília: MP, SEGES, 2008.

PEREIRA, L. C. B. Gestão do setor público: estratégia e estrutura para um novo Estado. In: PEREIRA, L. C. B.; SPINK, P. Reforma do Estado e administração pública gerencial. 7· ed. Rio de Janeiro: FGV, 2006.

.Gestão do setor público: estratégia e estruturação CTQG, Câmara Técnica de Qualidade do Gasto. Sistemas de informação de custos no Governo Federal: orientações para o desenvolvimento e implantação de metodologia e Sistema de geração e emprego de informações de custos no Governo Federal. Brasília: SOF, 2008.

Reforma do Estado para a cidadania: a reforma gerencial brasileira na perspectiva internacional. Rio de Janeiro: Editora 34/ENAP, 1998.

FERLIE, E. et al. A nova administração pública em ação. Brasília: UNB/ENAP, 1999.

FUNDO NACIONAL DE DESENVOLVIMENTO DA EDUCAÇÃO - FNDE. Alimentação escolar: apresentação. Disponível em <http://www.fnde.gov.br/index.php/programas-alimentacao-escolar>. Acessado em 11 abr. 2010.

GAO - UNITED STATES GOVERNMENT ACCOUNTABILITY OFFICE. Normas de auditoria governamental Revisão 2003. Salvador: Tribunal de Contas do Estado da Bahia, 2005.

INTERNATIONAL ORGANIZATION OF SUPREME AUDIT INSTITUTIONS - INTOSAI. Diretrizes para aplicação de normas de auditoria operacional: normas e diretrizes para a auditoria operacional baseadas nas Normas de Auditoria e na experiência prática da INTOSAI. Salvador: Tribunal de Contas do Estado da Bahia, 2005.

KAPLAN, R. S.; COOPER, R. Custo \& desempenho: administre seus custos para ser mais competitivo. São Paulo: Futura, 1998.

JENKINS, K. A reforma do serviço público no Reino Unido. In: PEREIRA, L. C. B.; SPINK, P. Reforma do Estado e administração pública gerencial. 7· ed. Rio de Janeiro: FGV, 2006.

MINISTÉRIO DA EDUCAÇÃO - MEC. Resolução/CD/FNDE № 38, DE 16 DE JULHO DE 2009. Disponível em <http://www.fnde.gov.br>. Acessado em 11 abr. 2010.

OSBORNE, D.; GAEBLER, T. Reinventando o governo: como o espírito empreendedor está transformando o setor público. 4. ed. Brasília: MH Comunicação, 1994.

PLANO DE AÇÃO CONTRA A CRISE: modernização das lideranças nacionais (inclusive Governo, Congresso e Sociedade) para transformar crise em oportunidade. Rio de Janeiro: INAE, 2009. 
RIBEIRO, R. P. et al. Desafios e evolução na Controladoria Geral da União: adaptação das práticas de avaliação de programas face às perspectivas da nova administração pública. In: CONGRESSO VIRTUAL BRASILEIRO DE ADMINISTRAÇÃO, 5, 2008. Anais... Rio de Janeiro, CONVIBRA, 2008

SHANK, J. K.; GOVINDARAJAN, V. A revolução dos custos: como reinventar e redefinir sua estratégia de custos para vencer em mercados crescentemente competitivos. 6. ed. Rio de Janeiro: Campus, 1997.

SLOMSKI, V. et al. Governança corporativa e governança na gestão pública. São Paulo: Atlas, 2008. 